\title{
Mitochondria and the Lectin Pathway of Complement ${ }^{*}$
}

Received for publication, October 23, 2012, and in revised form, January 28, 2013 Published, JBC Papers in Press, February 1, 2013, DOI 10.1074/jbc.M1 12.430249

\section{Christel R. Brinkmann ${ }^{\ddagger}$, Lisbeth Jensen ${ }^{\ddagger}$, Frederik Dagnæs-Hansen ${ }^{\ddagger}$, Ida E. Holm ${ }^{\varsigma \uparrow}$, Yuichi Endo", Teizo Fujita", Steffen Thiel ${ }^{\ddagger}$, Jens C. Jensenius ${ }^{\ddagger}$, and Søren E. Degn ${ }^{\ddagger 1}$}

From the ${ }^{\ddagger}$ Department of Biomedicine, Faculty of Health Sciences, and "Institute of Clinical Medicine, Aarhus University, DK-8000 Aarhus C, Denmark, the ${ }^{\S}$ Laboratory for Experimental Neuropathology, Department of Pathology, Randers

Hospital, DK-8930 Randers NØ, Denmark, and the "Department of Immunology, Fukushima Medical University, 1-Hikariga-oka, Fukushima City, Fukushima 960-1295, Japan

Background: Mitochondria are remnants of a eubacterial endosymbiont and may elicit untoward inflammation.

Results: MBL, L-ficolin, and M-ficolin recognize mitochondria. MBL binding activates complement. Upon mitochondrial challenge, C3 is consumed in vivo in the absence of overt inflammation.

Conclusion: The lectin pathway may be involved in homeostatic clearance of mitochondria.

Significance: This is the first indication of lectin pathway involvement in mitochondrial immune handling.

Mitochondria, the powerhouses of our cells, are remnants of a eubacterial endosymbiont. Notwithstanding the evolutionary time that has passed since the initial endosymbiotic event, mitochondria have retained many hallmarks of their eubacterial origin. Recent studies have indicated that during perturbations of normal homeostasis, such as following acute trauma leading to massive necrosis and release of mitochondria, the immune system might mistake symbiont for enemy and initiate an inappropriate immune response. The innate immune system is the first line of defense against invading microbial pathogens, and as such is the primary suspect in the recognition of mitochondriaderived danger-associated molecular patterns and initiation of an aberrant response. Conversely, innate immune mechanisms are also central to noninflammatory clearance of innocuous agents. Here we investigated the role of a central humoral component of innate immunity, the lectin pathway of complement, in recognition of mitochondria in vitro and in vivo. We found that the soluble pattern recognition molecules, mannan-binding lectin (MBL), L-ficolin, and M-ficolin, were able to recognize mitochondria. Furthermore, MBL in complex with MBL-associated serine protease 2 (MASP-2) was able to activate the lectin pathway and deposit $\mathrm{C} 4$ onto mitochondria, suggesting that these molecules are involved either in homeostatic clearance of mitochondria or in induction of untoward inflammatory reactions. We found that following mitochondrial challenge, C3 was consumed in vivo in the absence of overt inflammation, indicating a potential role of complement in noninflammatory clearance of mitochondria. Thus, we report here the first indication of involvement of the lectin pathway in mitochondrial immune handling.

Mitochondria are the powerhouses of our cells. They arose more than 1.5 billion years ago by the engulfment of an $\alpha$-pro-

\footnotetext{
* This work was supported by a postdoctoral grant from the Carlsberg Foundation (to S. E. D.).

${ }^{1}$ To whom correspondence should be addressed: Dept. of Biomedicine, Aarhus University, Bartholin Bldg., Wilhelm Meyers Allé 4, DK-8000 Aarhus C, Denmark. Tel.: 45-871-67274; Fax: 45-8619-6128; E-mail: sdegn@microbiology.au.dk.
}

teobacterium by an archaeon forming an endosymbiotic relationship and giving rise to the ancestor of all eukaryotic cells (1). Notwithstanding the evolutionary time that has passed since this event, mitochondria have retained many hallmarks of their eubacterial origin, including a circular, albeit heavily reduced, genome, unique tRNA and ribosomal entities, and a double membrane. This has led to the suggestion that during perturbations of normal homeostasis, such as following acute trauma leading to massive necrosis and release of mitochondria, the immune system might mistake symbiont for enemy and initiate an inappropriate immune response (2).

The innate immune system is the first line of defense against invading microbial pathogens, and as such would be the primary suspect in the recognition of mitochondria-derived danger-associated molecular patterns and initiation of an aberrant response. Conversely, innate immune mechanisms are also central to noninflammatory clearance of innocuous agents. A primary component of the innate immune system is complement, a proteolytic cascade system in serum comprising three pathways of activation: the classical pathway, the lectin pathway, and the alternative pathway (3). The lectin pathway is, in evolutionary terms, the oldest of the three (4). It is governed by the pattern recognition molecules $(\mathrm{PRMs})^{2}$ mannan-binding lectin (MBL) and the three ficolins (H-, L-, and M-ficolin), which recognize carbohydrate and acetylated patterns, respectively. MBL and ficolins form large homo-oligomers that circulate in complex with MBL-associated serine proteases (MASP-1, -2, and -3) as well as small nonenzymatic MBL-associated proteins (MAp19 and MAp44) (5). MASP-2 is the protease responsible for cleaving complement components $\mathrm{C} 4$ and $\mathrm{C} 2$, forming the $\mathrm{C} 3$ convertase of the lectin pathway, $\mathrm{C} 4 \mathrm{~b} 2 \mathrm{a}(6)$. We and others have recently shown that human MASP-1 is crucially involved in lectin pathway activation through the

\footnotetext{
${ }^{2}$ The abbreviations used are: PRM, pattern recognition molecule; $\mathrm{MBL}$, mannan-binding lectin; $r M B L$, recombinant MBL; MASP, MBL-associated serine protease; MAp, MBL-associated protein; DKO, double knock-out(s); TOMM22, translocase of the outer mitochondrial membrane 22 homolog; MPO, myeloperoxidase; RAG2, recombination activating gene 2; HSA, human serum albumin; CVF, cobra venom factor; ANOVA, analysis of variance; CpG, 5-cytosine-phosphoguanine; FMT, flow mannitol.
} 
transactivation of MASP-2 $(7,8)$, an observation spurred by a previous demonstration of MASP-1 involvement in the lectin pathway in mice (9). MASP-3 does not appear to be involved in complement (7), whereas the MAps have been suggested to play regulatory roles (5).

Complement is an important inducer of inflammatory responses toward microorganisms. Genetically determined deficiency of MBL, the most common primary immunodeficiency, may lead to recurrent infections when other redundant arms of the immune system are suppressed $(10,11)$. Immunodeficiency has also been reported as a consequence of defects in MASP-2 (12), M-ficolin (13), and H-ficolin $(14,15)$. However, as any other immune mechanism, the lectin pathway of complement is a double-edged sword, and bystander damage or aberrant responses initiated by the lectin pathway may be involved in the pathogenesis of autoimmune responses. Thus, deficiency of MBL or inhibition of MASP-2 prevents ischemia reperfusion injuries (16), and a high level of MBL leads to excess cardiovascular complications and earlier death in type 1 diabetes patients (17). Complement also plays an important role in the resolution of inflammation by promoting the safe clearance of apoptotic cells and immune complexes through the cooperative action of its soluble PRMs, opsonins, and receptors (18, 19 ), and deficiencies in complement components may promote autoimmune conditions (20). Human $\mathrm{H}$ - and L-ficolin have been reported to bind apoptotic cells and to activate complement (21), whereas mouse ficolin B (orthologue of human M-ficolin) was recently reported to bind both apoptotic and necrotic cells (22), indicating that ficolins may play a role in the removal of damaged host cells and maintenance of tissue homeostasis. Importantly, massive activation and depletion of complement has been observed following traumatic injury (23).

We hypothesized that the lectin pathway might play an important role in immune handling of released mitochondria, either as a homeostatic mechanism promoting mitochondrial clearance or through the initiation of untoward inflammatory responses. To examine our hypothesis, we analyzed the role of the lectin pathway in recognition of mitochondria in vitro and in vivo. The in vivo studies were conducted in MBL double knock-out (DKO) mice, MBL/RAG2 triple knock-outs, ficolin A knock-out mice, and ficolin B knock-out mice. Although humans have one functional MBL gene (MBL2) and a pseudogene (MBL1), both mouse orthologues (MBL-C and MBL-A, respectively) are functional (24), necessitating the use of double knock-outs. Conversely, the mouse orthologue of human $\mathrm{H}$-ficolin is a pseudogene, whereas human L- and M-ficolin correspond to mouse ficolin A and ficolin B, respectively (25).

\section{EXPERIMENTAL PROCEDURES}

Purification of Mitochondria-Purification of mitochondria from liver was carried out essentially as described by Pallotti and Lenaz (26) for the purification of mitochondria from rat liver. All steps were performed on ice. Briefly, 1-3 livers were harvested from mice or rats, transferred to mannitol buffer (210 mM mannitol, 70 mm sucrose, 5 mm Tris- $\mathrm{HCl}, 1 \mathrm{~mm}$ EDTA, $\mathrm{pH}$ 7.5), and mechanically disrupted. Large pieces were pelleted by gravity for $1 \mathrm{~min}$, and the supernatant was homogenized using 10 strokes in a Dounce homogenizer. The homogenate was centrifuged at 3,000 $\times g$ for $2 \mathrm{~min}$. The supernatant was recovered and recentrifuged at $17,500 \times g$ for $3 \mathrm{~min}$. The pellet was washed twice with $10 \mathrm{ml}$ of mannitol buffer, centrifuging first 3 $\mathrm{min}$ and then $5 \mathrm{~min}$ at $17,500 \times \mathrm{g}$. Finally, the pellet was resuspended in fresh mannitol buffer using $10 \mathrm{ml}$ of buffer $/ 7 \mathrm{~g}$ of liver. Purified mitochondria were always used fresh, except for immunoblotting, where samples were stored at $-80^{\circ} \mathrm{C}$ until use.

Immunoblotting and Flow Cytometric Analyses of Purified Mitochondria-For immunoblotting, samples were prediluted with TBS (10 mm Tris- $\mathrm{HCl}, 145 \mathrm{~mm} \mathrm{NaCl}, \mathrm{pH}$ 7.4) to give equal load volumes, and samples were added to $1 / 4$ volume of SDSPAGE sample buffer (62.5 mM Tris, $8 \mathrm{~m}$ urea, $10 \%$ (v/v) glycerol, $3 \%(\mathrm{w} / \mathrm{v})$ SDS, $0.001 \%(\mathrm{w} / \mathrm{v})$ bromphenol blue, $\mathrm{pH}$ 6.7) and then loaded onto a Criterion TGX 4-15\% gel (Bio-Rad). The gel was run in Tris/glycine buffer before being semidry blotted onto a polyvinylidene difluoride membrane (Bio-Rad). The membrane was blocked in $0.1 \%$ Tween 20 in TBS and then incubated with rabbit anti-Hsp60 (kindly provided by Svend Birkelund) diluted $1 / 1,000$ in primary buffer (TBS containing $0.05 \%$ Tween 20 (TBS/T), 1 mm EDTA, 1 mg of human serum albumin (HSA; CSL Behring) $/ \mathrm{ml}$, and $100 \mu \mathrm{g}$ of normal human IgG (Beriglobin, CSL Behring) $/ \mathrm{ml}$ ). The membrane was washed, incubated with HRP-conjugated goat anti-rabbit Ig (P0448, DAKO) in secondary buffer (TBS/T, no azide, $1 \mathrm{~mm}$ EDTA, and $100 \mu \mathrm{g}$ of human IgG/ml), and washed again before being developed with SuperSignal West Dura extended duration substrate (Pierce). Blots were also developed directly with HRP-conjugated anti$\beta$-actin (A3854, Sigma) in secondary buffer. Images were taken using a charge-coupled device camera (LAS-3000; Fuji) and analyzed with the Image Analysis Software supplied with the camera.

Flow cytometry analyses of mitochondrial preparations were performed on a FACSAria III (four-laser) at the FACS core facility at the Faculty of Health Sciences, Aarhus University. Mitochondria were stained with MitoTracker Red CMXRos (M7512) (kindly provided by Thomas Corydon) or MitoTracker Deep Red FM (M22426) (Invitrogen, Molecular Probes), as well as mouse monoclonal anti-TOMM22 antibody (1C9 2, ab57523, Abcam).

PRM Binding to Mitochondria Coated in Microtiter WellsMitochondrial preparations were resuspended and diluted in TBS as indicated, then added to the wells of FluoroNunc microtiter plates (Nunc), $100 \mu \mathrm{l} /$ well, and incubated $2 \mathrm{~h}$ at $4{ }^{\circ} \mathrm{C}$. The wells were washed thrice with TBS containing $0.1 \%$ HSA and incubated 30 min with the final wash. Recombinant MBL (27), recombinant M-ficolin (28), purified L-ficolin (29), or purified $\mathrm{H}$-ficolin (30) was diluted to $1 \mu \mathrm{g} / \mathrm{ml}$ in either TBS, $0.1 \% \mathrm{HSA}$, $5 \mathrm{mM} \mathrm{CaCl}_{2}$ or TBS, $0.1 \%$ HSA, $10 \mathrm{~mm}$ EDTA and then incubated overnight at $4{ }^{\circ} \mathrm{C}$ in the mitochondria-coated wells. After washing thrice with TBS, $0.1 \% \mathrm{HSA}, 5 \mathrm{mM} \mathrm{CaCl}_{2}$, the wells were incubated with in-house biotinylated antibody to MBL (131-1 (31)), M-ficolin (7G1 (28)), L-ficolin (GN5, Hycult Biotech), or $\mathrm{H}$-ficolin (4H5, Hycult Biotech) at $1 \mu \mathrm{g} / \mathrm{ml}$ TBS, $0.1 \% \mathrm{HSA}, 5$ $\mathrm{mM} \mathrm{CaCl}_{2}$ for $2 \mathrm{~h}$ at $4{ }^{\circ} \mathrm{C}$. The wells were washed as before, and $\mathrm{Eu}^{3+}$-labeled streptavidin in TBS, 0.1\% HSA, $25 \mu \mathrm{M}$ EDTA was added to the wells. After incubating for $1 \mathrm{~h}$ at room temperature, the wells were again washed as before and developed by 


\section{Mitochondria and the Lectin Pathway of Complement}

the addition of enhancement buffer $(0.57 \% \mathrm{v} / \mathrm{v}$ acetic acid, $0.1 \%$ $\mathrm{v} / \mathrm{v}$ Triton X-100, $1 \% \mathrm{w} / \mathrm{v}$ polyethylene glycol 6000, $15 \mu \mathrm{M}$ 2-naphthoyltrifluoroacetone, $50 \mu \mathrm{M}$ tri-(n-octyl)phosphine oxide, $\mathrm{pH} 3.2$, with potassium hydrogen phthalate) followed by measurement of time-resolved fluorescence on a Victor3 plate reader (PerkinElmer Life Sciences).

MBL Binding to Mitochondria in Suspension-Purified mitochondria were diluted $1 / 8$ in either TBS, $0.1 \% \mathrm{HSA}, 5 \mathrm{mM} \mathrm{CaCl}_{2}$ or TBS, 0.1\% HSA, 10 mm EDTA, and recombinant MBL (rMBL (27)) was added to a final concentration of $1 \mu \mathrm{g} / \mathrm{ml}$. The samples were incubated $2 \mathrm{~h}$ at $4{ }^{\circ} \mathrm{C}$ end-over-end. Mitochondria were pelleted at $17,500 \times g, 5 \mathrm{~min}, 4{ }^{\circ} \mathrm{C}$, and the supernatant was retrieved. $\mathrm{MBL}$ remaining in the supernatant was measured by incubation of 5-fold diluted supernatant in anti-MBL antibody (131-1, $5 \mu \mathrm{g} / \mathrm{ml}$ )-coated microtiter wells followed by $3 \times$ wash and development with $\mathrm{Eu}^{3+}$-labeled anti-MBL antibody (131-1, $0.5 \mu \mathrm{g} / \mathrm{ml})$.

Enzyme Digestion of Coated Mitochondria-Mitochondria, coated onto microtiter wells as before, were treated enzymatically with 10-fold dilution series of various enzymes for 1 or $3 \mathrm{~h}$, as follows: sialidase (Sigma) starting from 1.8 units/ml PBS, $\mathrm{pH}$ 6.0; $N$-glycosidase F (Roche Applied Science) starting from 10 units/ml PBS, pH 7.4, 10 mм EDTA; trypsin (Gibco) starting from $0.25 \%(\mathrm{w} / \mathrm{v})$ in PBS, pH 7.4, $10 \mathrm{~mm}$ EDTA; proteinase $\mathrm{K}$ (Qiagen) starting from 60 milli-arbitrary units/ml TBS, pH 7.4, $5 \mathrm{mM} \mathrm{CaCl}_{2}$. MBL binding assays were conducted as above, using 0.2 and $1.0 \mu \mathrm{g} \mathrm{rMBL} / \mathrm{ml}$.

Analysis of MBL Binding in Presence of Serum-To analyze the ability of MBL to bind mitochondria in the presence of serum, 10-fold dilution series of rMBL were prepared in 10-fold dilution series of serum, in either TBS, 0.1\% HSA, $5 \mathrm{mM} \mathrm{CaCl}_{2}$ or TBS, $0.1 \%$ HSA, 10 mm EDTA. The preparations were incubated in wells coated with mitochondria, and MBL binding was analyzed as before.

C4 Deposition by Bound MBL-MASP-2-Microtiter wells were coated with mannan, $10 \mu \mathrm{g} / \mathrm{ml}$ coating buffer, or purified mitochondria diluted $1 / 100$ or $1 / 1,000$ in TBS, 2 h at $4{ }^{\circ} \mathrm{C}$. Wells were washed thrice with TBS, $0.1 \%(\mathrm{w} / \mathrm{v})$ HSA, incubating 30 min with the final wash to block residual binding sites. A 5-fold dilution series of rMBL starting from 1,000 ng/ml TBS, $0.1 \%$ HSA, $5 \mathrm{~mm} \mathrm{CaCl}_{2}$ or TBS, $0.1 \%$ HSA, $5 \mathrm{~mm} \mathrm{CaCl}_{2}, 100 \mathrm{~mm}$ mannose, was added to the wells and incubated overnight at $4{ }^{\circ} \mathrm{C}$. The wells were washed thrice with TBS, $0.1 \%$ HSA, and then we added either in-house biotinylated anti-MBL (131-1) at $1 \mu \mathrm{g} / \mathrm{ml}$ TBS, $0.1 \% \mathrm{HSA}, 5 \mathrm{~mm} \mathrm{CaCl} \mathrm{Cl}_{2}$ or rMASP-2 at 200 or 50 $\mathrm{ng} / \mathrm{ml} \mathrm{TBS,} 0.1 \% \mathrm{HSA}, 5 \mathrm{~mm} \mathrm{CaCl}_{2}$. After a 1.5 -h incubation at $4{ }^{\circ} \mathrm{C}$, wells were washed as before. Wells were directly developed for MBL by the addition of $\mathrm{Eu}^{3+}{ }^{3+}$-streptavidin in TBS, $0.1 \%$ HSA, $25 \mu \mathrm{M}$ EDTA, incubation for $1 \mathrm{~h}$ at $4{ }^{\circ} \mathrm{C}$, a final wash $3 \times$, and the addition of enhancement buffer. In parallel, the wells that received MASP-2 were assayed for C4 deposition as activated MASP-2 will cleave $\mathrm{C} 4$ and the resulting $\mathrm{C} 4 \mathrm{~b}$ fragments bind covalently to the proteins coated on the surface of the wells. This was tested by the addition of purified C4, $2 \mu \mathrm{g} / \mathrm{ml} \mathrm{B1}$ buffer ( $4 \mathrm{~mm}$ barbital, $145 \mathrm{~mm} \mathrm{NaCl}, 2 \mathrm{mM} \mathrm{CaCl}_{2}$, and $1 \mathrm{~mm}$ $\mathrm{MgCl}_{2}, \mathrm{pH} 7.4$ ) and incubation for $1.5 \mathrm{~h}$ at $37^{\circ} \mathrm{C}$. After washing thrice as before, in-house biotinylated monoclonal anti-C4b antibody (162-02, BioPorto) was added to wells, at $0.5 \mu \mathrm{g} / \mathrm{ml}$
TBS, 0.1\% HSA, $5 \mathrm{~mm} \mathrm{CaCl}_{2}$. The wells were incubated $1.5 \mathrm{~h}$ at $4{ }^{\circ} \mathrm{C}$, washed thrice as before, and then $\mathrm{Eu}^{3+}$-streptavidin was added, and the wells were developed as before.

C3 Deposition from Human Serum-Microtiter wells were coated with mannan or mitochondria, blocked, and washed as before. The wells were then incubated for $1 \mathrm{~h}$ at $37^{\circ} \mathrm{C}$ with a 2-fold dilution series of a human serum pool, starting from 1/5 in TBS, $0.1 \% \mathrm{HSA}$, containing either $5 \mathrm{mM} \mathrm{CaCl}_{2}$ or $10 \mathrm{~mm}$ EDTA. The wells were washed three times with TBS, 0.1\% HSA, $5 \mathrm{~mm} \mathrm{CaCl}{ }_{2}$ and then incubated with in-house biotinylated anti-human C3c, $0.5 \mu \mathrm{g} / \mathrm{ml} \mathrm{TBS,} \mathrm{0.1 \%} \mathrm{HSA,} 5 \mathrm{~mm} \mathrm{CaCl}_{2}$, and developed with europium-labeled streptavidin as before.

Flow Cytometric Analysis of PRM Binding to Purified Mitochondria-Samples for flow analysis were prepared in flow mannitol (FMT) buffer (mannitol buffer containing 0.5\% HSA and $5 \mathrm{mM} \mathrm{CaCl}_{2}$ ). Mitochondrial preparations were diluted 10-fold in FMT buffer, then we added MBL, H-, L-, or M-ficolin to $10 \mu \mathrm{g} / \mathrm{ml}$ final concentration in $100 \mu \mathrm{l}$ of buffer and incubated $30 \mathrm{~min}$ at $4{ }^{\circ} \mathrm{C}$. The mitochondria were washed twice by resuspending in $2 \mathrm{ml}$ of FMT buffer and centrifuging 3,000 $\times g$ for $5 \mathrm{~min}$ before being resuspended in $100 \mu \mathrm{l}$ of FMT buffer, and then primary antibody was added at $10 \mu \mathrm{g} / \mathrm{ml}$ final concentration. After incubating $30 \mathrm{~min}$ at $4{ }^{\circ} \mathrm{C}$, the mitochondria were washed as before, and phycoerythrin-conjugated secondary anti-mouse immunoglobulins (DAKO R0439) were added. After a final incubation for $30 \mathrm{~min}$ at $4{ }^{\circ} \mathrm{C}$, samples were washed as before, resuspended in $500 \mu \mathrm{l}$ of FMT buffer, and then analyzed by flow cytometry.

Intravenous Injection of Mitochondria-An initial titration of purified mitochondria was performed. Twelve C57BL/ 6JBomTac mice (Taconic, Denmark) older than 9 weeks of age were divided into groups of three and injected intravenously in the tail vein with purified mouse mitochondria corresponding to $0.05,0.25,1.25$, or $6.25 \%$ of the total mitochondrial content in one mouse liver. No effect was seen following observation for $24 \mathrm{~h}$. For the subsequent experiments, injection volumes were chosen to correspond to $\sim 7.5$ or $15 \%$ of total liver mitochondrial content. Mice were weighed before and after injections, e.g. 2 days before, at time of injection, and at termination of the experiment, 2, 3, or $24 \mathrm{~h}$ after. Similarly, serum was taken at various time points before and after injection. As a control for inflammation, LPS was injected intraperitoneally at 120 $\mu \mathrm{g} /$ mouse. The mouse strains used were $\mathrm{Mbl1}^{-1-}, \mathrm{Mbl2}^{-1-}$ DKO (B6.129S4-Mbl1 ${ }^{\text {tm1Kata }}$ Mbl2 $2^{\text {tm1Kata }}$ ), MBL DKO crossed with $R A G 2^{-1-}$ (B6.129S6-RAG2 $\left.2^{\text {tm1Fwa }}\right)$ in our animal facility to yield triple knock-outs, Fcna knock-outs (B6.129-Fcna $\left.{ }^{t m 1 T e f u}\right)$, and Fcnb knock-outs (B6.129-Fcnb $\left.{ }^{\text {tm1Tefu}}\right)$.

Cobra Venom Factor (CVF) Pretreatment and Assay of Remaining C3 Deposition Capacity ex Vivo-10-fold serial titrations of a preparation of CVF (kindly provided by Edzard Spillner (32)) were injected into WT mice. The mice were monitored for toxicity reactions, and $2 \mathrm{~h}$ following injections, blood was drawn and assayed for remaining C3 deposition capacity. Briefly, microtiter wells were coated with zymosan (Sigma), 20 $\mu \mathrm{g} / \mathrm{ml}$ coating buffer $\left(15 \mathrm{~mm} \mathrm{Na}_{2} \mathrm{CO}_{3}, 35 \mathrm{~mm} \mathrm{NaHCO}, \mathrm{pH} 9.6\right)$ and then blocked with TBS containing $1 \mathrm{mg} / \mathrm{ml}$ HSA. After being washed with TBS/T 20 thrice, the wells were incubated for $45 \mathrm{~min}$ at $37^{\circ} \mathrm{C}$ with serum samples diluted in $\mathrm{B} 1$ buffer. 
Wells were washed thrice with $\mathrm{TBS} / \mathrm{T} / \mathrm{Ca}^{2+}$, then incubated with rat-anti-mouse C3 (Connex, D-82152) $0.5 \mu \mathrm{g} / \mathrm{ml}$ TBS/T/ $\mathrm{Ca}^{2+}$. The wells were washed as before and incubated with biotinylated anti-rat immunoglobulin (Dako, E0468) $0.5 \mu \mathrm{g} / \mathrm{ml}$ $\mathrm{TBS} / \mathrm{T} / \mathrm{Ca}^{2+}$ and then developed as described above. A dilution $(1 / 10,000)$ of the CVF preparation was chosen, which provided a marked but incomplete reduction in remaining $\mathrm{C} 3$ deposition capacity in the absence of overt toxicity. Mice were pretreated with this dose of CVF or vehicle alone 24 and $2 \mathrm{~h}$ prior to challenge with mitochondria or sham. Two hours following challenge, blood was drawn for IL-6 (below) and C3 deposition analysis (as above).

MPO and IL-6 Assays-Myeloperoxidase (MPO) was measured in lung tissue from mice injected with mitochondria using a commercial MPO assay kit (Hbt mouse MPO ELISA test kit, Hycult Biotechnology), according to the manufacturer's instructions. IL- 6 was measured in serum using the mouse IL-6 DuoSet ELISA kit (DY406, R\&D Systems), according to the manufacturer's instructions.

Histology-The mice were sacrificed, and the lungs were fixed in a $10 \%$ formaldehyde solution. Standard histological preparation of the lung tissue was performed, including paraffin embedding and subsequent $H \& E$ staining of $6-8-\mu m$-thick paraffin sections.

Statistical Analyses-Statistical analyses were performed using GraphPad Prism 5, as indicated.

\section{RESULTS}

Purification of Mitochondria and Validation of Mitochondrial Preparations-Mitochondria were purified from mouse or rat livers according to a well established method based on homogenization, mechanical cell lysis, and differential centrifugation (26). To characterize the mitochondrial preparations, they were analyzed by immunoblotting and by flow cytometry.

The Western blots of the mitochondria were developed either with rabbit anti-human Hsp60, cross-reactive with mouse Hspd1 (97\% amino acid identity), as a mitochondrionspecific marker or with directly HRP-conjugated mouse-antihuman $\beta$-actin, cross-reactive with mouse $\beta$-actin ( $100 \%$ identity), as a general cell marker. As can be seen in Fig. $1 A$, through the purification procedure, we retain Hspd1 $(\sim 61 \mathrm{kDa})$, whereas we see a gradual depletion of $\beta$-actin $(\sim 43 \mathrm{kDa})$, indicating a gradual enrichment of mitochondrial proteins.

To determine whether our mitochondrial preparations indeed contained intact mitochondria, and not only mitochondrial proteins, we analyzed them by flow cytometry, by staining with MitoTracker, a dye specific for mitochondria, or with mouse-anti-human TOMM22 (a component protein of the translocase of the outer mitochondrial membrane), cross-reactive with mouse TOMM22. As can be seen in Fig. $1 B$, the forward and side scatter plot revealed two populations: population 1, presumably intact mitochondria, and population 2, presumably cellular and mitochondrial debris (possibly copurified lysosomal components according to Ref. 26). Indeed, population 1 stained for the mitochondrial marker TOMM22 (Fig. 1C), whereas population 2 did not (Fig. 1D). The majority of the mitochondrial 1 population was stained by TOMM22, but not by the secondary antibody alone when compared with back-
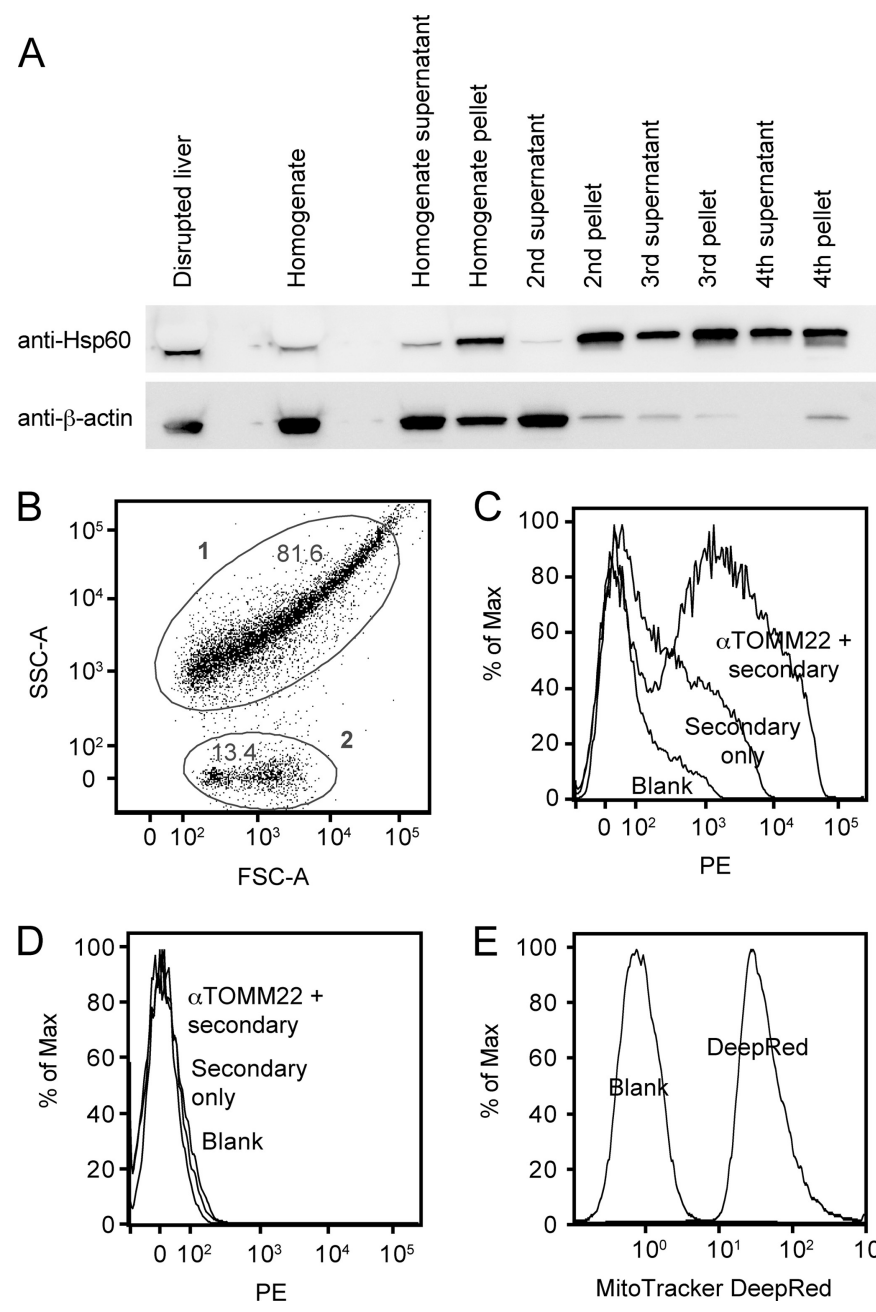

FIGURE 1. Analysis of mitochondrial purification and preparations. $A$, immunoblots for Hsp60 (Hspd1) mitochondrial marker and $\beta$-actin general cellular marker. Fractions from the mitochondrial purification were subjected to reducing SDS-PAGE and transferred to PVDF and then probed with the antibodies. The fractions are as indicated under "Experimental Procedures," and the load volume of each fraction was normalized according to the fraction volume when compared with the starting volume. Note that the Hsp60 band is compressed by the high protein content in the first fractions. $B$, forward and side scatter dot plot of a mitochondrial preparation. FSC-A, forward scatter channel A; SSC-A, side scatter channel A. C, histogram showing phycoerythrin (PE)-labeled anti-TOMM22 staining of population 1 from panel $B$ versus secondary only and blank (unstained). \% of Max, percentage of maximum. $D$, histogram showing anti-TOM22 staining of population $\mathbf{2}$ from panel $B$ versus secondary only and blank (unstained). E, histogram showing MitoTracker DeepRed staining of a mitochondrial preparation from a separate experiment versus blank (unstained).

ground (unstained, blank). Conversely, the 2 population was not stained, indicating the specificity of the staining. As a further validation, a separate mitochondrial preparation displayed a marked shift upon staining with the mitochondrion-specific dye MitoTracker (Fig. 1E). We concluded that the mitochondrial preparation contained mostly intact mitochondria of an acceptable purity.

PRM Binding to Mitochondria Coated in Microtiter WellsThe ability of MBL and ficolins to bind purified mouse mitochondria was analyzed in an assay in which the mitochondria were coated directly in microtiter wells. As can be seen from Fig. 2, MBL, L-ficolin, and M-ficolin bound to directly coated mitochondria (Fig. 2, $A, B$, and $C$, respectively). The binding of 

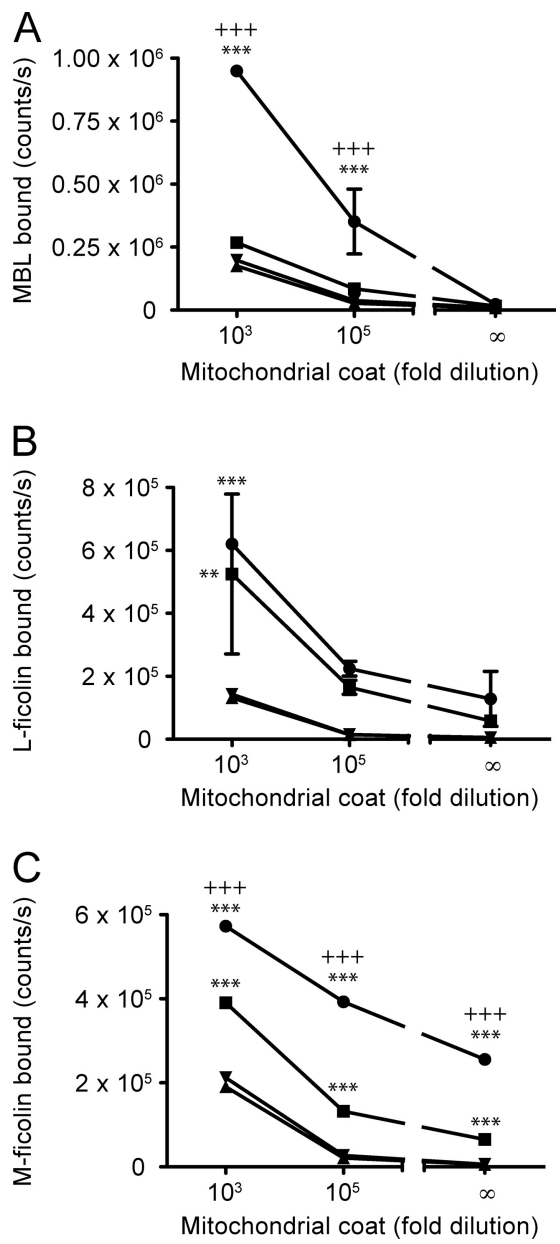

FIGURE 2. Binding of MBL and ficolins to mitochondria coated in microtiter wells. $A$, analysis of the binding of MBL in microtiter wells coated with two different concentrations of mitochondria or blocking buffer only., $\mathrm{MBL}$ at 1 $\mu \mathrm{g} / \mathrm{ml}$ in calcium-containing buffer; $\mathbf{\square}, \mathrm{MBL}$ at $1 \mu \mathrm{g} / \mathrm{ml}$ in EDTA-containing buffer; $\boldsymbol{\Lambda}$, calcium buffer only; $\boldsymbol{\nabla}$, EDTA buffer only. $B$, as in panel $A$, but for L-ficolin. $C$, as in panel A, but for M-ficolin. Error bars indicate S.D. of duplicate measurements. $A$ and $C$, representative of three independent experiments. $B$, representative of two independent experiments. Significant $p$ values are indicated for two-way ANOVA using Bonferroni's post test, when comparing mitochondrial coat with background for each buffer $\left(^{*}\right)$ or comparing mitochondrial coat with the two different buffers (+). Significance levels are defined as: ${ }^{* *}$ or $++<0.01$, and ${ }^{* * *}$ or $+++<0.001$.

MBL was dependent on calcium (Fig. 2A), in agreement with it being a C-type lectin, whereas the binding of L-ficolin was not dependent on $\mathrm{Ca}^{2+}$ (Fig. 2B), in agreement with previous studies $(33,34)$. The binding of $\mathrm{M}$-ficolin was partially calcium-dependent (Fig. 2C). We could not detect binding of $\mathrm{H}$-ficolin above background, as in the absence of $\mathrm{H}$-ficolin, the detecting antibody gave as high signals as in its presence (not shown). The picture was the same for all the PRMs when binding to mitochondria purified from rat liver was examined (not shown).

Binding of MBL to Mitochondria in Suspension, Effect of Enzymatic Treatment of Mitochondria, and Presence of Serum Proteins-To follow up on the observed binding to mitochondria coated in microtiter wells, the ability of MBL to bind mitochondria in suspension was analyzed. Recombinant MBL was incubated with mitochondria in either calcium-containing or EDTA-containing buffer, or alone without mitochondria as control. The mitochondria were then pelleted, and the amount of free MBL left in the supernatant was measured. As can be seen in Fig. $3 A$, incubation with mitochondria depleted about $50 \%$ of MBL from the supernatant when performed in the presence of calcium, whereas no MBL depletion was seen in the presence of EDTA or in the absence of mitochondria. This confirmed the $\mathrm{Ca}^{2+}$-dependent binding of MBL to intact mitochondria $(p<0.001$, one-way ANOVA using Tukey's multiple comparisons test).

To approach the question of surface-exposed ligands for MBL in a simple manner, we examined the effect of various enzymatic treatments of coated mitochondria on the binding of MBL. Although it is impossible to directly compare the effect of various enzymes because we cannot normalize their activities, it would appear that sialidase, as expected, did not significantly impact the binding activity, whereas $N$-glycosidase had some effect, and trypsin and proteinase $\mathrm{K}$ had significant impacts (Fig. 3B). Thus, by two-way ANOVA with Bonferroni's post test, when compared with untreated mitochondria (100\% binding), sialidase only produced a significant effect at its highest concentration $(p<0.001)$, whereas $N$-glycosidase was significant at the two higher concentrations $(p<0.001)$, and trypsin and proteinase $\mathrm{K}$ reached significance at all concentrations employed $(p<0.001)$. This may indicate the involvement of mitochondrial surface protein-linked glycosylations in the binding of MBL.

Having only examined binding of recombinant MBL in a system void of other serum components, the possibility remained that MBL would be prevented from binding in the presence of serum. To examine whether the observed binding was influenced by the presence of serum, we prepared dilutions of rMBL in dilutions of serum, in either a calcium-containing or an EDTA-containing buffer. Because MBL is a C-type lectin, its binding being totally dependent on calcium, the former would give the true signal plus background, and the latter would give the background signal only. In fact, we saw a reduction in both these signals as a function of an increase in serum. To determine whether the presence of serum was in fact impacting on our true signal, we plotted the signal:noise ratios (signal in calcium-containing buffer/signal in EDTA-containing buffer) at the various serum concentrations as a function of the concentration of MBL (Fig. 3C). We then fitted the curves using semilog linear regression and examined whether the fitted curves conformed to the same model or were indeed different. Analysis by Akaike's information criterion indicated that the probability of the curves conforming to one curve was $>99.99 \%$, leading us to conclude that serum does not influence the observed true signal arising from binding of MBL to mitochondria.

PRM Binding to Mitochondria Analyzed by Flow CytometryBinding of MBL and ficolins to mitochondria was also analyzed by flow cytometry (Fig. 4). As can be seen, MBL (Fig. 4A) and $\mathrm{L}$-ficolin (Fig. 4B) bound to mitochondria. Binding of M-ficolin and $\mathrm{H}$-ficolin could not be determined due to high nonspecific binding of the detecting antibodies (not shown). The MBL binding was also analyzed by using directly biotinylated MBL, which gave a much better signal (Fig. 4C). To rule out any possible interference from binding of murine MBL or antibodies during purification, mitochondria were also purified from MBL/RAG2 triple knock-outs (deficient in MBL and B and T 

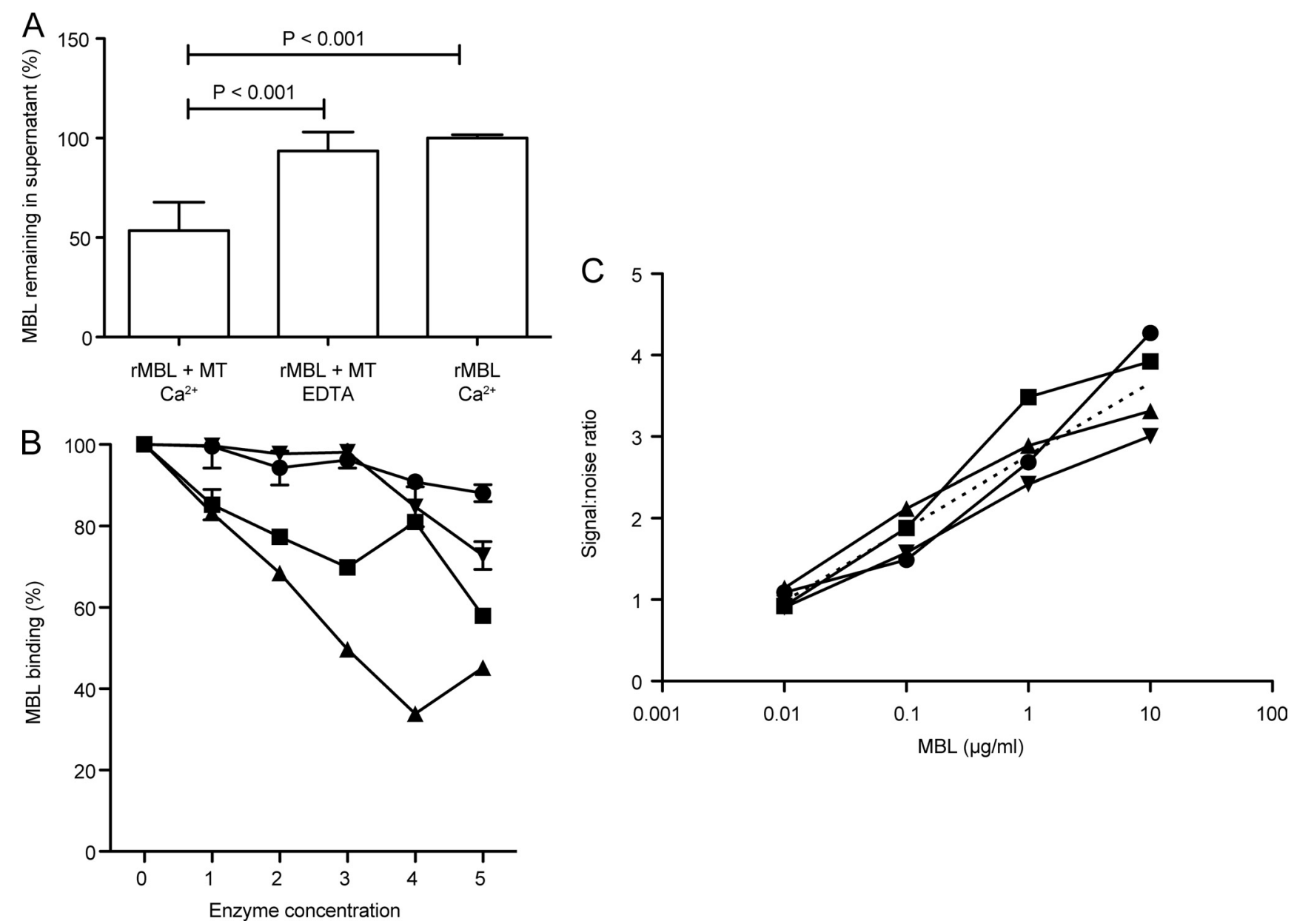

FIGURE 3. Binding of MBL to mitochondria in suspension, analysis of effect of enzyme digestion on binding, and analysis of MBL binding in presence of serum. $A$, the percentage of MBL remaining in supernatant after incubation with mitochondria in a calcium-containing or an EDTA-containing buffer when compared with incubation without mitochondria (relative to amount of MBL added). Mean with S.D. based on six measurements in four independent experiments. Significant $p$ values are indicated for one-way ANOVA with Tukey's multiple comparison test. $B$, binding of MBL (1 $\mu \mathrm{g} / \mathrm{ml})$ to mitochondrial coat treated with various enzymes: sialidase $(\mathbf{O}), \mathrm{N}$-glycosidase $\mathrm{F}(\boldsymbol{\nabla})$, trypsin $(\boldsymbol{\square})$, and proteinase $\mathrm{K}(\mathbf{\Delta})$, at the concentrations given in under "Experimental Procedures." Error bars indicate S.D. of duplicate measurements. Similar results were obtained for 1 and $0.2 \mu \mathrm{g} \mathrm{MBL} / \mathrm{ml}$, in two independent experiments with similar conditions (1- and 3-h digests). $C$, analysis of binding of MBL to mitochondrial coat in the presence $(1 / 10 \boldsymbol{0}, 1 / 100 \mathbf{\square}$, and $1 / 1,000 \mathbf{\Delta})$ and absence $(\mathbf{\nabla})$ of serum. The curves indicate the signal:noise ratios for MBL binding to mitochondrial coat 1/100, defined as the ratio of observed signal in a calcium-containing buffer versus an EDTA-containing buffer (background as MBL is a C-type lectin), as a function of the concentration of MBL. Curves were fitted using nonlinear regression with a semilog model. The best fit values of the y-intercept and slope of the different curves were compared using Akaike's information criterion, resulting in a probability of one curve for all data sets of $>99.99 \%$. The consensus curve is indicated (straight dashed line).

lymphocytes, and hence also deficient in antibodies), which gave a result similar to that of mitochondria purified from BALB/c mice (Fig. 4D).

C4 Deposition by MBL-MASP-2 Bound to MitochondriaWe have previously analyzed the ability of MBL-MASP-2 complexes to activate and deposit $\mathrm{C} 4$ fragments in microtiter wells (see, for example, Ref. 7). As a control of our setup, we again tested this and indeed found MBL in complex with MASP-2 to be able to activate complement upon binding to mannan in an MBL concentration-dependent manner, inhibitable by mannose (Fig. 5, $A$ and $B$ ). To assess a possible role of the mitochondrial binding of MBL in complement activation, we analyzed the C4 deposition capacity of MBL-MASP-2 bound to mitochondria. As before, mitochondria were coated directly in microtiter wells and then incubated with MBL, MASP-2, and finally purified C4. We observed an MBL concentration-dependent deposition of $\mathrm{C} 4$ fragments on the mitochondria, inhibitable by mannose (Fig. $5 \mathrm{C}$ ). The $\mathrm{C} 4$ deposition activity corre- sponded well with the amount of MBL actually bound in the wells (Fig. 5D).

Intravenous Injection of Mitochondria-Having established that MBL, L-ficolin, and M-ficolin are able to bind mitochondria and that bound MBL in complex with MASP-2 is able to deposit $\mathrm{C} 4$ on mitochondria, thus activating the lectin pathway of complement, we proceeded to analyze a possible effect in vivo. An initial titration with purified mitochondria corresponding to $0.05,0.25,1.25$, or $6.25 \%$ of total liver mitochondrial content was performed (four groups, $n=3$ each). Others have used mitochondria equivalent to a $5 \%$ liver injury (2). We observed no effect during $24 \mathrm{~h}$ of observation. For the subsequent experiments, we chose to use mitochondria corresponding to $\sim 7.5$ and $15 \%$ of total liver volume. This gave no overt response in wild-type mice either. Sham-injected or LPS-injected $(120 \mu \mathrm{g} /$ mouse, given intraperitoneally) groups were included. Histopathological examination of lung tissue sections from the mice was performed. Microscopy of H\&E-stained sec- 

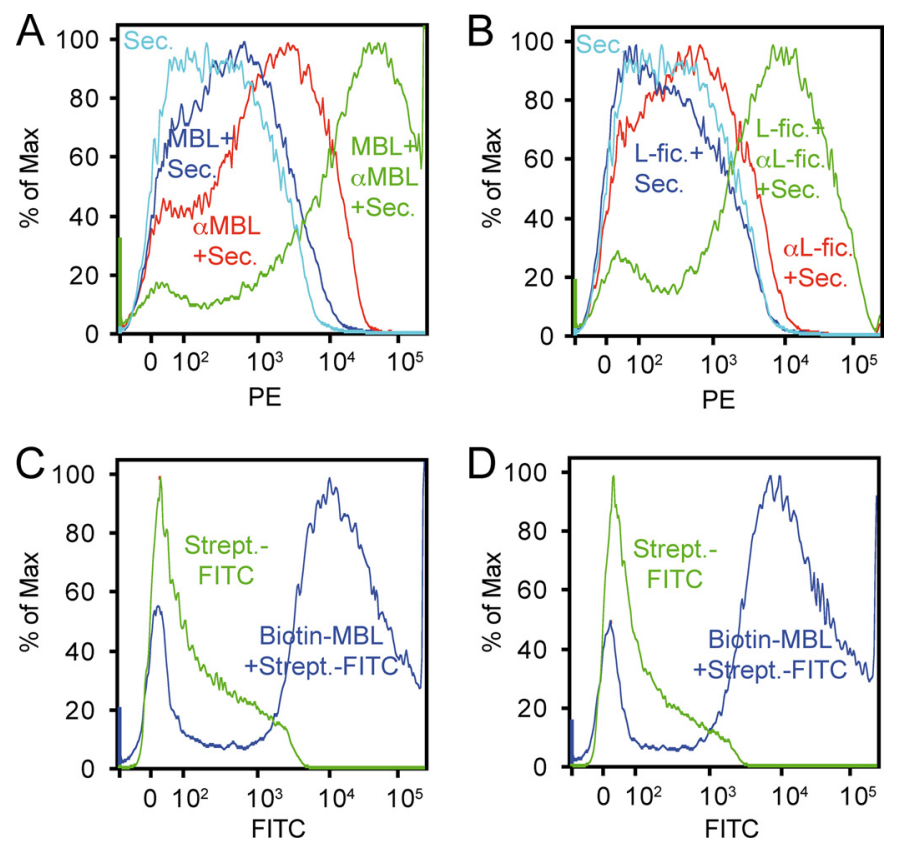

FIGURE 4. Flow cytometric analysis of binding of MBL and L-ficolin to mitochondria. $A$, binding of $M B L$ to mitochondria detected with anti-MBL followed by phycoerythrin (PE)-labeled secondary rabbit $\mathrm{F}\left(\mathrm{ab}^{\prime}\right)_{2}$ anti-mouse immunoglobulins $(M B L+\alpha M B L+$ Sec., green line), omitting MBL $(\alpha M B L+$ Sec., red line), omitting anti-MBL (MBL + Sec., dark blue line), or secondary antibody only (Sec., light blue line). \% of Max, percentage of maximum. B, as in panel $A$, but for $L$-ficolin ( $L$-fic.). $C$, binding of biotinylated MBL to mitochondria purified from BALB/c mice, detected with streptavidin-FITC (Biotin-MBL Strept.-FITC, blue line) versus streptavidin-FITC alone (Strept.-FITC, green line). $D$, as in panel $C$, but for mitochondria purified from MBL/RAG2 knock-outs.

tions from the lungs was performed blindly to detect any possible difference in inflammatory response between mice of either group. All lungs appeared without any discernible acute inflammation (Fig. 6), even the LPS group, although two of six mice were sacrificed prior to the $24 \mathrm{~h}$ mark due to significant weight loss. Polymorphonuclear leukocyte infiltration of lungs following intraperitoneal LPS administration has been reported to increase 7.5 -fold at $0.5 \mathrm{~h}$ after injection, but in the absence of diapedesis and tissue damage (35). The possibility remained that deficiency in MBL, L-ficolin, or M-ficolin might render the mice susceptible to inflammation upon mitochondrial challenge by preventing normal homeostatic clearance.

We first sought to examine the role of intact versus disrupted (sonicated, as in Ref. 2) mitochondria in the context of three different types of mice: 1) MBL- and antibody-deficient (MBL $\mathrm{DKO} / \mathrm{RAG}^{-/-}$, i.e. triple knock-outs), 2) MBL-deficient only (MBL DKO), or 3) wild-type mice (C57BL/6). Injection of mitochondria corresponding to total $15 \%$ liver injury did not induce any apparent inflammatory response in either group based on analysis of MPO in lungs and IL-6 in serum (Kruskal-Wallis with Dunn's post test, $\alpha=0.05$ ) (Fig. 7) and histopathology as before (not shown). Furthermore, there was no significant decrease in weight when comparing the weight before and after the injection of mitochondria for each group (two-way ANOVA with Bonferroni's post test, $\alpha=0.05$ ).

Next we examined the response of ficolin A or B knock-outs when compared with wild-type toward intact mitochondria (15\% equivalent), including a positive control in the form of LPS and a negative control buffer only. As can be seen in Fig. 8, none of the groups responded to mitochondrial challenge or buffer only, whereas all responded to LPS injection, as assayed by measurement of serum levels of IL-6 before and after injection (for this assay, measurements below detection limit were set to 0 , whereas measurements above detection limit were set to $1,000 \mathrm{pg} / \mathrm{ml}$ ). Together, these results indicate that although MBL, L-ficolin, and M-ficolin are able to bind mitochondria, and MBL is able to activate complement upon binding, no one component is singularly responsible for any observed effect in vivo, attesting to the redundancy of homeostatic immune mechanisms.

Deposition of C3 in Vitro, Mitochondrial Challenge, and Complement Activation in Vivo-Returning to a possible effect of mitochondrial challenge in vivo and a potential role of complement, we examined the central component of complement, C3. Firstly, we asked whether mitochondria might afford not only MBL binding, MASP-2 activation, and C4 deposition, as we had already seen, but also deposition of downstream C3 from human serum. To answer this question, we coated microtiter wells with either mitochondria, or as a positive control, mannan. We then incubated the wells with human serum in either a calcium-containing or an EDTA-containing buffer. As can be seen in Fig. 9, both mannan (Fig. 9A) and mitochondria (Fig. $9 B$ ) supported activation of complement and deposition of C3 from human serum in vitro.

We subsequently asked whether such activation and hence consumption of $\mathrm{C} 3$ might be occurring in vivo, perhaps in the absence of overt inflammation. To address this, we challenged mice with mitochondria, sham, or LPS in the presence or absence of pretreatment with CVF, a substance short-circuiting the alternative pathway leading to uncontrolled consumption of C3. We had titrated the amount of CVF to a nontoxic dose, providing partial depletion of $\mathrm{C} 3$. Following the challenge, we analyzed the capacity for $\mathrm{C} 3$ deposition remaining in the blood of the animals by a C3 deposition assay on zymosan. As can be seen in Fig. 9C, although mice injected with buffer or LPS had comparable levels of remaining $\mathrm{C} 3$ deposition capacity, the level of $\mathrm{C} 3$ deposition capacity in mice receiving mitochondria or CVF alone was suppressed (albeit not statistically significant), whereas it was markedly reduced in the mice receiving both CVF and mitochondria (one-way ANOVA, $p=0.0219$, with Tukey's multiple comparison test, $p<0.05$ ). Notably, our analysis of IL-6 levels in the blood (Fig. 9D) indicated that this activation occurred in the absence of inflammation as only the LPS control group gave rise to a significant increase in IL-6 levels (one-way ANOVA, $p<0.0001$, with Tukey's multiple comparison test, $p<0.001$ ). Taken together, this indicates that mitochondria, like CVF, activate complement in vivo, and together they present a cumulative effect, but this occurs in the absence of overt inflammation.

\section{DISCUSSION}

In general, the immune system distinguishes self from nonself by sensing structures unique to pathogens. In innate immunity, this recognition is mediated by pattern recognition receptors such as Toll-like receptors (TLRs) (36) and humoral PRMs such as MBL and the ficolins (H-, L-, or M-ficolin) of the lectin pathway of complement or $\mathrm{C1q}$ of the classical pathway. 


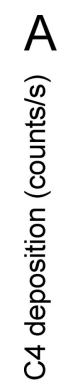
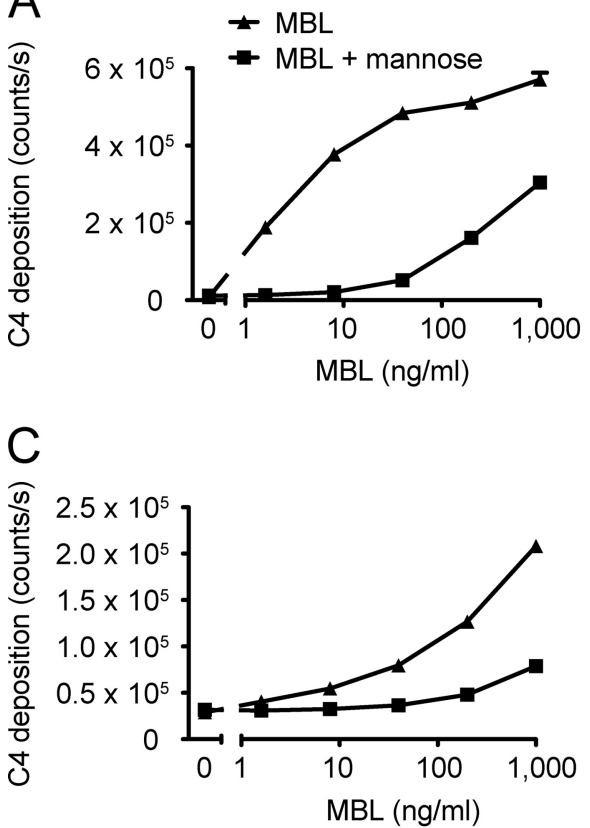

B

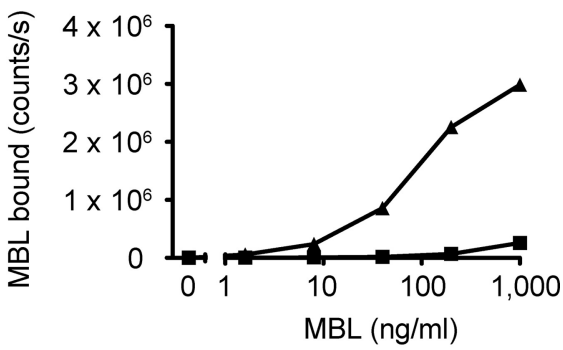

$\mathrm{D}$

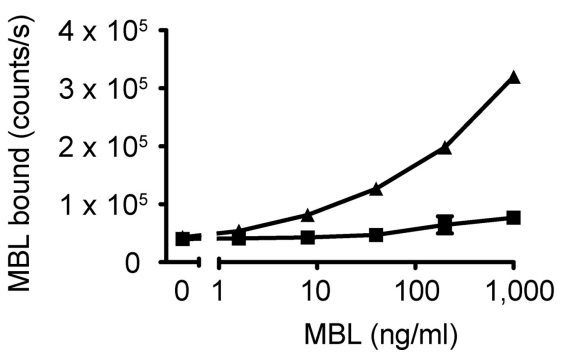

FIGURE 5. MBL-MASP-2-mediated complement activation on mitochondria. A, MBL-MASP-2-mediated C4 deposition in mannan-coated microtiter wells as a function of MBL concentration (fixed MASP-2 conc. at $50 \mathrm{ng} / \mathrm{ml}$ ), in the absence ( $\boldsymbol{\Delta}$ ) or presence $(\square)$ of 100 mM mannose. $B$, MBL bound to the mannan measured in parallel wells. $C$, as in panel $A$, but for mitochondrial coat $(1 / 1,000)$. $D$, as in panel $B$, but for mitochondrial coat. Error bars indicate S.D. of duplicate measurements. Experiments performed with two different concentrations of MASP-2 $(50 \mathrm{ng} / \mathrm{ml}$ or $200 \mathrm{ng} / \mathrm{ml})$ and two different coating concentrations of purified mitochondria $(1 / 100$ or $1 / 1,000)$ gave similar results.
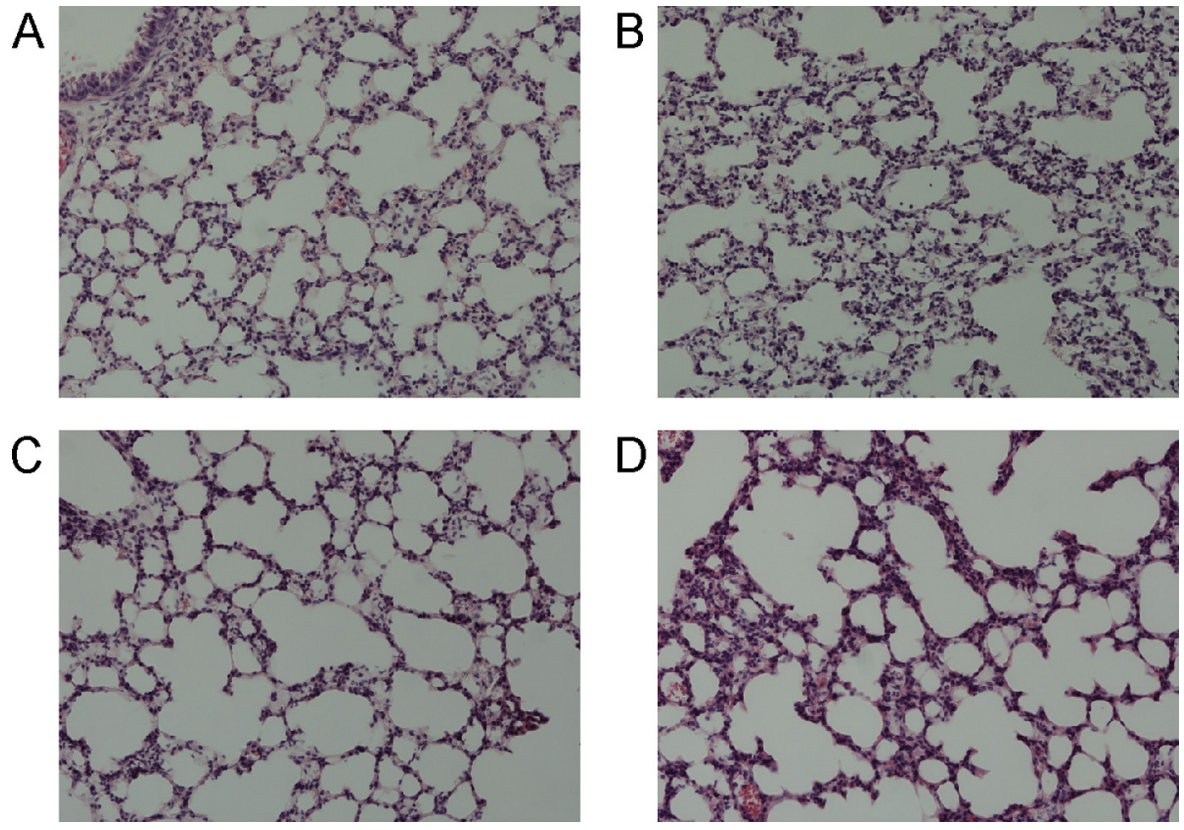

FIGURE 6. Histological analysis of lung sections following injection of mitochondria, sham, or LPS. $A, 15 \%$ of total mitochondrial content of liver injected intravenously. $B, 7.5 \%$ of total mitochondrial content of liver injected intravenously. C, buffer alone injected intravenously. D, $120 \mu \mathrm{g}$ of LPS injected intraperitoneally. Results are representative of six mice analyzed for each group, except the LPS group, where two mice were sacrificed before the conclusion of the experiment due to significant weight loss. Pictures were taken at $200 \times$ magnification.

It has previously been suggested that the classical pathway of complement is involved in inflammatory reactions to mitochondria. Consumption of classical complement components by heart subcellular membranes in vitro and in patients after acute myocardial infarction was noted many years ago (37). Although subsequent work cast doubt upon these findings (38), more recent work has again made a connection by implicating
C1q-mediated mitochondria-driven oxidative stress in neonatal hypoxic-ischemic brain injury (39).

Here we examined a possible role of the lectin pathway in recognition of released mitochondria in vitro and in vivo. We observed binding to mitochondria of MBL, L-ficolin, and M-ficolin, and MBL-MASP-mediated C4 deposition, as well as C3 deposition from human serum, indicating that these compo- 

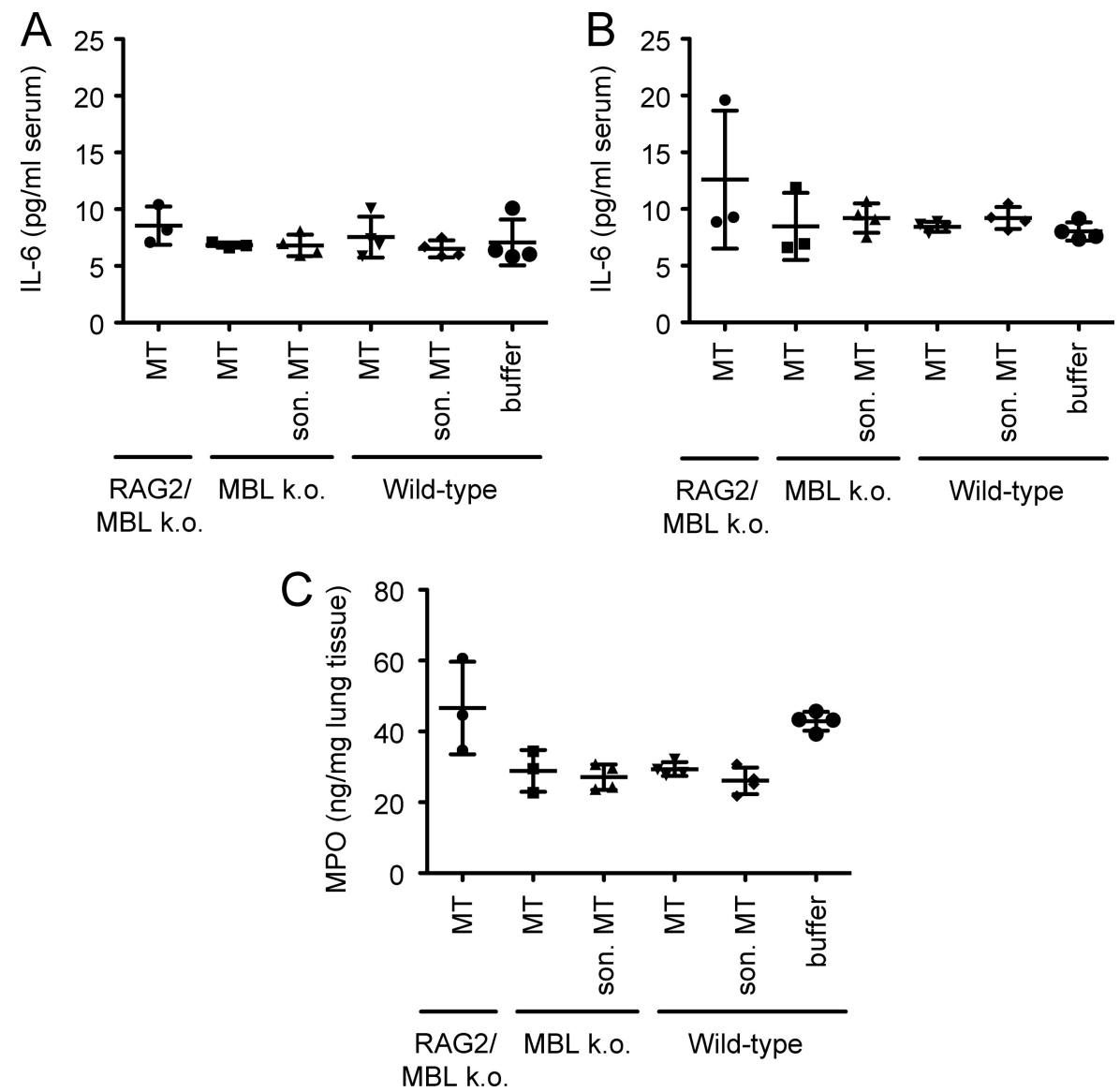

FIGURE 7. Analysis of response to mitochondria in vivo in RAG2/MBL knock-outs and MBL knock-outs versus wild-type C57BL/6 mice. $A$, IL-6 measured in serum before injection of intact or disrupted purified mitochondria or buffer only. MT, mitochondria. son. MT, sonicated mitochondria. RAG2/MBL $k$. O., RAG2/MBL knock-out; MBL k. o., MBL knock-out. B, IL-6 measured in serum after injection of intact or disrupted purified mitochondria or buffer only. $C$, MPO measured in lung tissue after injection of intact or disrupted purified mitochondria or buffer only. Mean and S.D. are indicated for each group.
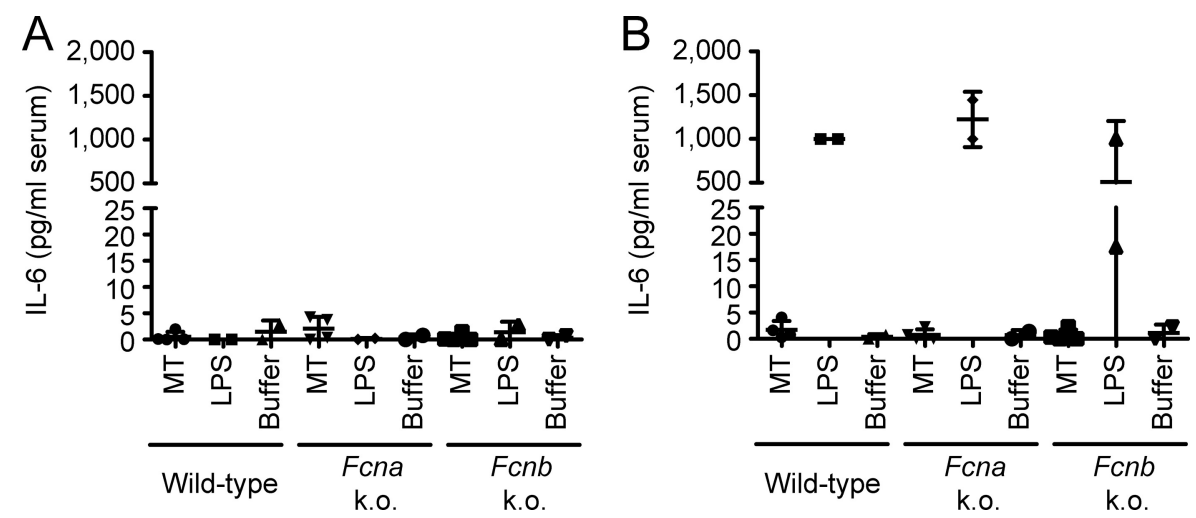

FIGURE 8. Analysis of response to mitochondria in vivo in Fcna knock-outs and Fcnb knock-outs versus wild-type C57BI/6 mice. $A$, IL-6 measured in serum before injection of intact purified mitochondria, LPS, or buffer only. MT, mitochondria; Fcna k. O., Fcna, knock-out; Fcnb k. O., Fcnb, knock-out. B, IL-6 measured in serum after injection of intact mitochondria, LPS, or buffer only. Mean and S.D. are indicated for each group.

nents may be involved either in homeostatic clearance of or untoward inflammatory reactions to released mitochondria. Somewhat surprisingly, injection of purified mitochondria into WT mice and MBL, ficolin-A, or ficolin-B knock-out mice did not result in any marked inflammatory response, as evidenced by the absence of weight loss and base-line systemic IL- 6 measurements as well as MPO assays and histological analysis of lungs. However, Zhang et al. (2) also reported only a minor accumulation of IL-6 in rat lungs after mitochondrial challenge
(15 pg/mg of protein) when compared with naive or medium only (10 pg/mg of protein).

It has previously been noted that mitochondria injected into rabbits or rats are efficiently cleared from the circulation predominantly by Kupffer cells in the liver (40, 41). McCully et al. (42) found that local injection of isolated mitochondria in the heart of rabbits during early reperfusion resulted in cardioprotection. Ischemia induces mitochondrial damage and dysfunction that persist throughout reperfusion, and it was hypothe- 

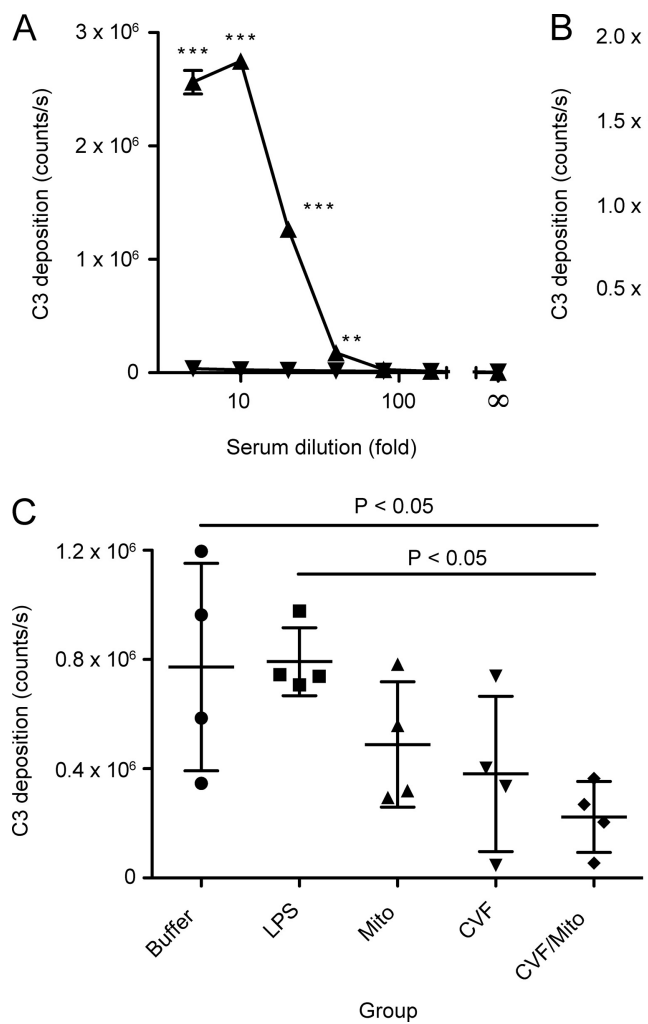
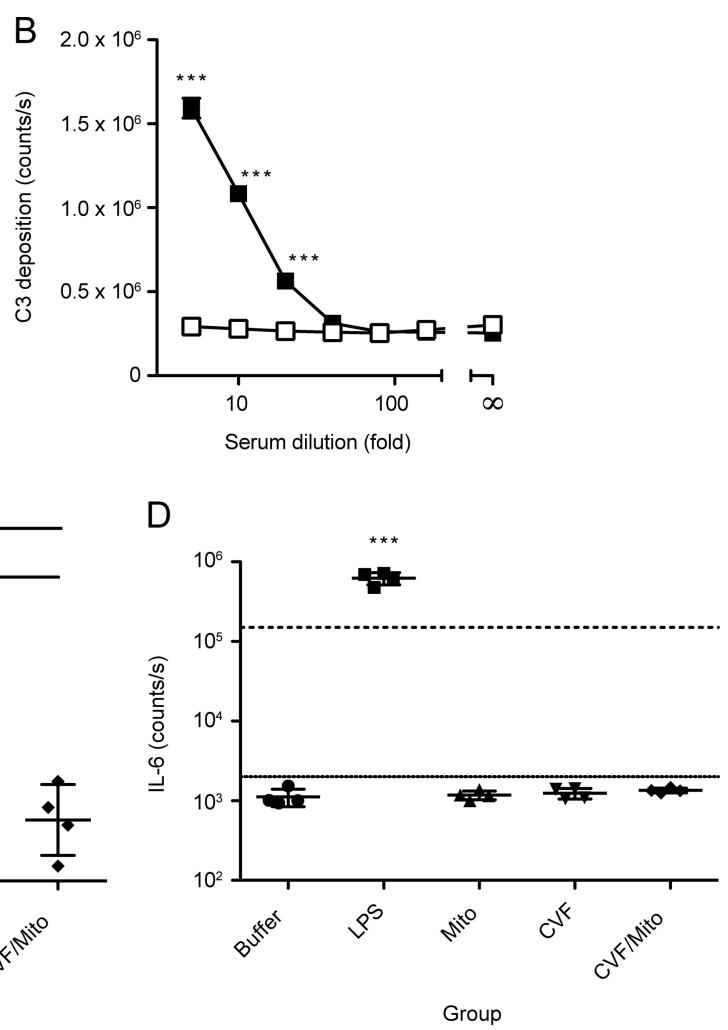

FIGURE 9. C3 deposition from human serum onto mitochondria and analysis of C3 deposition capacity remaining and IL- 6 levels in murine sera after mitochondrial challenge. $A, C 3$ deposition from human serum onto a mannan surface in either calcium-containing ( $(\mathbf{\Lambda})$ or EDTA-containing $(\mathbf{\nabla})$ buffer. $B, C 3$ deposition from human serum onto a mitochondrial surface in either calcium-containing ( $\square$ ) or EDTA-containing ( $\square)$ buffer. In $A$ and $B$, error bars indicate S.D. of mean for duplicates. C, assay of remaining C3 deposition capacity on zymosan following in vivo challenge with buffer, LPS, or mitochondria (Mito), with or without pretreatment with CVF. D, measurement of IL-6 levels in the samples presented in panel C. The raw counts/s are given. The limits of the internal standard curve are indicated (top line, 1,000 pg/ml 150,000 counts/s; bottom line, $8 \mathrm{pg} / \mathrm{ml} \sim 2,500$ counts $/ \mathrm{s}$ ). In C and D, mean and S.D. are indicated for each group.

sized that viable respiration-competent mitochondria, isolated from tissue unaffected by ischemia and then injected into the ischemic zone just before reperfusion, would enhance postischemic functional recovery and limit infarct size. In neither of these studies were any adverse effects of mitochondrial administration noted, indicating homeostatic clearance under normal circumstances, in agreement with our observations here.

Not only has the immune system evolved to efficiently clear mitochondria without initiating an inflammatory response; it would also seem that mitochondria have co-evolved to lose some of their proinflammatory potential. The major pathogenassociated molecular pattern of Gram-negative bacteria, encompassing $\alpha$-proteobacteria and hence the protomitochondrion, is lipopolysaccharide of the outer membrane. However, in mitochondria, the lipid composition of the outer membrane resembles that of the eukaryotic plasma membrane and does not contain LPS (43). Although the outer mitochondrial membrane does contain porins with similar ultrastructure and function to that of Gram-negative bacteria, there is no apparent evolutionary link between these (43), suggesting that they may be perceived by the immune system as two different entities. The "counter-inflammatory co-evolution" may also be evidenced by the pervasive $\mathrm{CpG}$ suppression observed in animal mitochondrial genomes (44), leading to a scarcity of such potential unmethylated $\mathrm{CpG}$ messengers of inflammation. In addition, the level of $\mathrm{CpG}$ methylation was recently reported to have been significantly underestimated in previous studies (45), indicating that remaining $\mathrm{CpG}$ motifs are not significantly unmethylated and hence do not readily elicit inflammation. Finally, the reduction in the mitochondrial genome size (46) may further serve to reduce immune incompatibility. Together, these observations indicate adaptive changes increasing immunological compatibility of mitochondria with their hosts. Nonetheless, a recent study has reported that mitochondrial DNA that escapes from autophagy may cause inflammation and heart failure (47). This became evident upon cardiac-specific deletion of lysosomal deoxyribonuclease (DNase) II and challenge with pressure overload. Wild-type mice similarly subjected to pressure overload were not prone to the TLR9-mediated cardiac inflammation as they more efficiently cleared mitochondrial DNA through the action of DNase II. Hence, a number of homeostatic mechanisms operate under normal circumstances to protect against untoward inflammation elicited by mitochondrial endosymbionts.

Recent studies have highlighted the role of mitochondrial danger signals in untoward inflammation following acute trauma (2) and cardiac pressure overload (47). Simultaneously, it has become clear that marked complement activation and consumption occur upon traumatic injury (23). Linking these observations, we have provided here the first step toward a characterization of the involvement of the lectin pathway in homeostatic clearance of mitochondria. We have demon- 
strated that MBL, L-ficolin, and M-ficolin recognize mitochondria and that MBL binding activates the lectin pathway. However, in vivo not one of these molecules was singly involved in the response to mitochondria. The redundancy of the various molecules, pathways, and effector mechanisms hinders analysis by single-molecule knock-outs. Nonetheless, we have provided the first evidence of an involvement of the lectin pathway in mitochondrial immune handling by our in vitro studies and by our observation that mitochondria activate $\mathrm{C} 3$ in vivo in the absence of overt inflammation. This ties in nicely with the well appreciated role of complement as a mediator of homeostatic clearance, deficiencies of which predispose to autoimmune conditions such as lupus. However, to fully appreciate the role of the lectin pathway and complement at large in mitochondrial immune handling, future studies should examine the roles of simultaneous knock-out of multiple effector arms and/or central components such as C4 and C3.

Acknowledgments-We are grateful to Annette Thomsen and Anni Skovbo at the FACS core facility, Faculty of Health Sciences, Aarhus University, for assistance with the flow cytometry. We thank Annette G. Hansen for help with the MPO ELISA. We thank Thomas Corydon for sharing extensive insight regarding mitochondrial purification and characterization. Edzard Spillner kindly provided purified CVF.

\section{REFERENCES}

1. Dyall, S. D., Brown, M. T., and Johnson, P. J. (2004) Ancient invasions: from endosymbionts to organelles. Science 304, 253-257

2. Zhang, Q., Raoof, M., Chen, Y., Sumi, Y., Sursal, T., Junger, W., Brohi, K., Itagaki, K., and Hauser, C. J. (2010) Circulating mitochondrial DAMPs cause inflammatory responses to injury. Nature 464, 104-107

3. Ricklin, D., Hajishengallis, G., Yang, K., and Lambris, J. D. (2010) Complement: a key system for immune surveillance and homeostasis. Nat. Immunol. 11, 785-797

4. Dodds, A. W. (2002) Which came first, the lectin/classical pathway or the alternative pathway of complement? Immunobiology 205, 340-354

5. Degn, S. E., Hansen, A. G., Steffensen, R., Jacobsen, C., Jensenius, J. C., and Thiel, S. (2009) MAp44, a human protein associated with pattern recognition molecules of the complement system and regulating the lectin pathway of complement activation. J. Immunol. 183, 7371-7378

6. Thiel, S., Vorup-Jensen, T., Stover, C. M., Schwaeble, W., Laursen, S. B., Poulsen, K., Willis, A. C., Eggleton, P., Hansen, S., Holmskov, U., Reid, K. B., and Jensenius, J. C. (1997) A second serine protease associated with mannan-binding lectin that activates complement. Nature 386, 506-510

7. Degn, S. E., Jensen, L., Hansen, A. G., Duman, D., Tekin, M., Jensenius, J. C., and Thiel, S. (2012) Mannan-binding lectin-associated serine protease (MASP)-1 is crucial for lectin pathway activation in human serum, whereas neither MASP-1 nor MASP-3 is required for alternative pathway function. J. Immunol. 189, 3957-3969

8. Héja, D., Kocsis, A., Dobó, J., Szilágyi, K., Szász, R., Závodszky, P., Pál, G., and Gál, P. (2012) Revised mechanism of complement lectin-pathway activation revealing the role of serine protease MASP-1 as the exclusive activator of MASP-2. Proc. Natl. Acad. Sci. U.S.A. 109, 10498-10503

9. Takahashi, M., Iwaki, D., Kanno, K., Ishida, Y., Xiong, J., Matsushita, M., Endo, Y., Miura, S., Ishii, N., Sugamura, K., and Fujita, T. (2008) Mannosebinding lectin (MBL)-associated serine protease (MASP)-1 contributes to activation of the lectin complement pathway. J. Immunol. 180, 6132-6138

10. Neth, O., Hann, I., Turner, M. W., and Klein, N. J. (2001) Deficiency of mannose-binding lectin and burden of infection in children with malignancy: a prospective study. Lancet 358, 614-618

11. Peterslund, N. A., Koch, C., Jensenius, J. C., and Thiel, S. (2001) Association between deficiency of mannose-binding lectin and severe infections after chemotherapy. Lancet 358, 637-638
12. Stengaard-Pedersen, K., Thiel, S., Gadjeva, M., Møller-Kristensen, M., Sørensen, R., Jensen, L. T., Sjøholm, A. G., Fugger, L., and Jensenius, J. C. (2003) Inherited deficiency of mannan-binding lectin-associated serine protease 2. N. Engl. J. Med. 349, 554-560

13. Schlapbach, L. J., Kessler, U., Thiel, S., Hansen, A. G., Nelle, M., Ammann, R. A., Aebi, C., and Jensenius, J. C. (2009) M-ficolin in the neonatal period: Associations with need for mechanical ventilation and mortality in premature infants with necrotising enterocolitis. Mol. Immunol. 46, $2597-2603$

14. Munthe-Fog, L., Hummelshøj, T., Honoré, C., Madsen, H. O., Permin, H., and Garred, P. (2009) Immunodeficiency associated with FCN3 mutation and ficolin-3 deficiency. N. Engl. J. Med. 360, 2637-2644.

15. Schlapbach, L. J., Thiel, S., Kessler, U., Ammann, R. A., Aebi, C., and Jensenius, J. C. (2011) Congenital H-ficolin deficiency in premature infants with severe necrotising enterocolitis. Gut 60, 1438-1439

16. Schwaeble, W. J., Lynch, N. J., Clark, J. E., Marber, M., Samani, N. J., Ali, Y. M., Dudler, T., Parent, B., Lhotta, K., Wallis, R., Farrar, C. A., Sacks, S., Lee, H., Zhang, M., Iwaki, D., Takahashi, M., Fujita, T., Tedford, C. E., and Stover, C. M. (2011) Targeting of mannan-binding lectin-associated serine protease- 2 confers protection from myocardial and gastrointestinal ischemia/reperfusion injury. Proc. Natl. Acad. Sci. U.S.A. 108, 7523-7528

17. Hansen, T. K., Tarnow, L., Thiel, S., Steffensen, R., Stehouwer, C. D., Schalkwijk, C. G., Parving, H. H., and Flyvbjerg, A. (2004) Association between mannose-binding lectin and vascular complications in type 1 diabetes. Diabetes 53, 1570-1576

18. Flierman, R., and Daha, M. R. (2007) The clearance of apoptotic cells by complement. Immunobiology 212, 363-370

19. Trouw, L. A., Blom, A. M., and Gasque, P. (2008) Role of complement and complement regulators in the removal of apoptotic cells. Mol. Immunol. 45, $1199-1207$

20. Degn, S. E., Jensenius, J. C., and Thiel, S. (2011) Disease-causing mutations in genes of the complement system. Am. J. Hum. Genet. 88, 689-705

21. Kuraya, M., Ming, Z., Liu, X., Matsushita, M., and Fujita, T. (2005) Specific binding of $\mathrm{L}$-ficolin and $\mathrm{H}$-ficolin to apoptotic cells leads to complement activation. Immunobiology 209, 689-697

22. Schmid, M., Hunold, K., Weber-Steffens, D., and Männel, D. N. (2012) Ficolin-B marks apoptotic and necrotic cells. Immunobiology 217, $610-615$

23. Burk, A. M., Martin, M., Flierl, M. A., Rittirsch, D., Helm, M., Lampl, L., Bruckner, U., Stahl, G. L., Blom, A. M., Perl, M., Gebhard, F., and HuberLang, M. (2012) Early complementopathy after multiple injuries in humans. Shock 37, $348-354$

24. Hansen, S., Thiel, S., Willis, A., Holmskov, U., and Jensenius, J. C. (2000) Purification and characterization of two mannan-binding lectins from mouse serum. J. Immunol. 164, 2610-2618

25. Endo, Y., Liu, Y., Kanno, K., Takahashi, M., Matsushita, M., and Fujita, T. (2004) Identification of the mouse $\mathrm{H}$-ficolin gene as a pseudogene and orthology between mouse ficolins A/B and human L-/M-ficolins. Genomics $\mathbf{8 4}, 737-744$

26. Pallotti, F., and Lenaz, G. (2001) Isolation and subfractionation of mitochondria from animal cells and tissue culture lines. Methods Cell Biol. 65, $1-35$

27. Jensenius, J. C., Jensen, P. H., McGuire, K., Larsen, J. L., and Thiel, S. (2003) Recombinant mannan-binding lectin (MBL) for therapy. Biochem. Soc. Trans. 31, 763-767

28. Wittenborn, T., Thiel, S., Jensen, L., Nielsen, H. J., and Jensenius, J. C. (2010) Characteristics and biological variations of M-Ficolin, a pattern recognition molecule, in plasma. J. Innate Immun. 2, 167-180

29. Krarup, A., Thiel, S., Hansen, A., Fujita, T., and Jensenius, J. C. (2004) L-ficolin is a pattern recognition molecule specific for acetyl groups. J. Biol. Chem. 279, 47513-47519

30. Zacho, R. M., Jensen, L., Terp, R., Jensenius, J. C., and Thiel, S. (2012) Studies of the pattern recognition molecule $\mathrm{H}$-ficolin: specificity and purification. J. Biol. Chem. 287, 8071-8081

31. Thiel, S., Bjerke, T., Hansen, D., Poulsen, L. K., Schiøtz, P. O., and Jensenius, J. C. (1995) Ontogeny of human mannan-binding protein, a lectin of the innate immune system. Pediatr. Allergy Immunol. 6, 20-23

32. Kölln, J., Braren, I., Bredehorst, R., and Spillner, E. (2007) Purification of 


\section{Mitochondria and the Lectin Pathway of Complement}

native and recombinant cobra venom factor using thiophilic adsorption chromatography. Protein Pept. Lett. 14, 475-480

33. Garlatti, V., Belloy, N., Martin, L., Lacroix, M., Matsushita, M., Endo, Y., Fujita, T., Fontecilla-Camps, J. C., Arlaud, G. J., Thielens, N. M., and Gaboriaud, C. (2007) Structural insights into the innate immune recognition specificities of $\mathrm{L}$ - and $\mathrm{H}$-ficolins. EMBO J. 26, 623-633

34. Gout, E., Garlatti, V., Smith, D. F., Lacroix, M., Dumestre-Pérard, C., Lunardi, T., Martin, L., Cesbron, J.-Y., Arlaud, G. J., Gaboriaud, C., and Thielens, N. M. (2010) Carbohydrate recognition properties of human ficolins: glycan array screening reveals the sialic acid binding specificity of Mficolin. J. Biol. Chem. 285, 6612-6622

35. Hirano, S. (1996) Migratory responses of PMN after intraperitoneal and intratracheal administration of lipopolysaccharide. Am. J. Physiol. 270, L836-845

36. Janeway, C. A., Jr., and Medzhitov, R. (2002) Innate immune recognition. Annu. Rev. Immunol. 20, 197-216

37. Pinckard, R. N., Olson, M. S., Giclas, P. C., Terry, R., Boyer, J. T., and O'Rourke, R. A. (1975) Consumption of classical complement components by heart subcellular membranes in vitro and in patients after acute myocardial infarction. J. Clin. Invest. 56, 740-750

38. Comis, A., and Easterbrook-Smith, S. B. (1985) C1q binding to mitochondria: a possible artefact? FEBS Lett. 185, 105-108

39. Ten, V. S., Yao, I., Ratner, V., Sosunov, S., Fraser, D. A., Botto, M., Sivasankar, B., Morgan, B. P., Silverstein, S., Stark, R., Polin, R., Vannucci, S. J., Pinsky, D., and Starkov, A. A. (2010) Complement component c1q mediates mitochondria-driven oxidative stress in neonatal hypoxic-ischemic brain injury. J. Neurosci. 30, 2077-2087

40. Glaumann, H., and Trump, B. F. (1975) Lysosomal degradation of cell organelles. III. Uptake and disappearance in Kupffer cells of intravenously injected isotope-labeled mitochondria and microsomes in vivo and in vitro. Lab. Invest. 33, 262-272

41. Glaumann, H., Berezesky, I. K., Ericsson, J. L., and Trump, B. F. (1975) Lysosomal degradation of cell organelles. I. Ultrastructural analysis of uptake and digestion of intravenously injected mitochondria by Kupffer cells. Lab. Invest. 33, 239-251

42. McCully, J. D., Cowan, D. B., Pacak, C. A., Toumpoulis, I. K., Dayalan, H., and Levitsky, S. (2009) Injection of isolated mitochondria during early reperfusion for cardioprotection. Am. J. Physiol. Heart Circ. Physiol. 296, $\mathrm{H} 94-\mathrm{H} 105$

43. Zeth, K., and Thein, M. (2010) Porins in prokaryotes and eukaryotes: common themes and variations. Biochem. J. 431, 13-22

44. Cardon, L. R., Burge, C., Clayton, D. A., and Karlin, S. (1994) Pervasive CpG suppression in animal mitochondrial genomes. Proc. Natl. Acad. Sci. U.S.A. 91, 3799-3803

45. Shock, L. S., Thakkar, P. V., Peterson, E. J., Moran, R. G., and Taylor, S. M. (2011) DNA methyltransferase 1, cytosine methylation, and cytosine hydroxymethylation in mammalian mitochondria. Proc. Natl. Acad. Sci. U.S.A. 108, 3630-3635

46. Adams, K. L., and Palmer, J. D. (2003) Evolution of mitochondrial gene content: gene loss and transfer to the nucleus. Mol. Phylogenet. Evol. 29, $380-395$

47. Oka, T., Hikoso, S., Yamaguchi, O., Taneike, M., Takeda, T., Tamai, T., Oyabu, J., Murakawa, T., Nakayama, H., Nishida, K., Akira, S., Yamamoto, A., Komuro, I., and Otsu, K. (2012) Mitochondrial DNA that escapes from autophagy causes inflammation and heart failure. Nature 485, 251-255 